Бабич Анна Анатольевна, Тер-Григорьянц Радмила Георгиевна, Котова Галина Леонидовна

\title{
СОВРЕМЕННЫЕ МЕТОДЫ, ИНСТРУМЕНТЫ И СРЕДСТВА ОБЕСПЕЧЕНИЯ ДОСТУПНОСТИ ДОПОЛНИТЕЛЬНОГО ОБРАЗОВАНИЯ ДЕТЕЙ РАЗЛИЧНЫХ КАТЕГОРИЙ (ДЛЯ РУКОВОДИТЕЛЕЙ ОБРАЗОВАТЕЛЬНЫХ ОРГАНИЗАЦИЙ) ${ }^{1}$
}

В статье представлены результаты исследования особенностей функционирования системы дополнительного образования детей, а также обозначены современные методы и инструменты обеспечения ее доступности для детей всех категорий. Анализ и оценка актуальньх показателей позволили выявить новые тенденции развития системы и предвидеть возможные риски и последствия предстоящих трансформаций. В исследовании представлена методика повышения уровня доступности дополнительного образования для руководителей образовательных организачий, реализуемая посредством специализированных методов и инструментов. Авторская позиция по вопросу наиболее эффективного применения средств обеспечения доступности программ дополнительного образования представлена посредством сетевой модели взаимодействия.

Ключевые слова: дополнительное образование детей, доступность, категории детей, специфика обучения.

\section{Anna Babich, Radmila Ter-Grigoryantz, Galina Kotova \\ MODERN METHODS, TOOLS AND MEANS OF MAKING ACCESSIBILITY \\ OF ADDITIONAL EDUCATION OF CHILDREN OF VARIOUS CATEGORIES \\ (FOR HEADS OF EDUCATIONAL ORGANIZATIONS)}

The article presents the results of a study of data of the system of additional education of children, and also outlines modern methods and tools to ensure its accessibility for children of all categories. The analysis and assessment of current indicators made it possible to identify new trends in the development of the system and anticipate the possible risks and consequences of the upcoming transformations. The study presents a methodology for increasing the accessibility of additional education for the leaders of educational organizations, implemented through specialized methods and tools. The author's position on the most effective use of accessibility tools for continuing education programs is presented through a network interaction model. instruction.

Key words: additional education of children, accessibility, categories of children, specifics of

Bведениe / Introduction. Отечественная система дополнительного образования детей (далее - ДОД) функционирует с целью построения специализированной образовательно-воспитательной сетевой среды, обеспечивающей равные условия для достижения социального и личностного роста детей различных категорий, в том числе детей с ограниченными возможностями здоровья (далее - ОВЗ), детей, проживающих в сельской местности, детей из семей, находящихся в трудной жизненной ситуации, из малоимуших семей.

Современная система ДОД, в отличие от стандартизированной системы государственного образования, ориентирована на реализацию индивидуального выбора каждого ребенка в соответствии с его природными склонностями, способностями и интересами, а также независимо

\footnotetext{
Исследование проведено в рамках проекта «Проведение экспертной оценки доступности дополнительного образования детей с учетом потребностей и особенностей детей различных категорий (в том числе детей с ограниченными возможностями здоровья, детей, проживающих в сельской местности, детей из семей, находящихся в трудной жизненной ситуации, детей из малоимущих семей)) (гос. контракт № 06 S05.11.0005 от 02.07.2019 г.)
} 
от его места жительства и социально-экономического статуса семьи. При этом область личностного развития ребенка не должна быть ограничена образовательной сферой, а включать также художественную, техническую, спортивную, научную и иную полезную деятельность.

Однако существующая социальная среда и рыночная конъюнктура не позволяют в полной мере предоставлять альтернативные возможности всем категориям детей в равной степени. На практике учреждения ДОД по-прежнему являются малодоступными для определенных категорий детей по причине нехватки финансовых ресурсов, территориальной отдаленности местности их проживания, наличия у детей OB'. Эти и иные факторы нарушают социальный баланс и конкурентную среду, реализуемые государством в части обеспечения справедливых условий для развития детей различных категорий в обществе, что особенно важно учитывать руководителям образовательных организаций.

Значительное число исследователей системы ДОД множество раз акцентировали свое внимание на проблеме доступности дополнительных программ развития детей, однако многие их предложения по ее решению не применимы на практике в силу потери их актуальности в современных условиях функционирования системы, а также малозначительности эффекта от их внедрения.

K примеру, О. И. Ануфриева, автор статьи «Дополнительное образование детей и взрослых», на основе проведенного исследования утверждает о целесообразности введения единых стандартов к реализации дополнительных общеобразовательных (общеразвивающих) программ, а также констатирует факт недостаточной сформированности государственного финансового механизма развития системы дополнительного образования [1]. В действительности описываемый автором метод не способен решить проблему доступности ДОД по нескольким причинам. Во-первых, внедрение стандартов может привести к нарушению прав организаций ДОД (в соответствии с ч. 5 ст. 75 Федерального закона от 29.12.2012 № 273-Ф3 «Об образовании в Российской Федерации» содержание дополнительных общеразвивающих программ разрабатывается и утверждается самим учреждением). Во-вторых, стандартизация деятельности повышает риск сокращения количества организаций, а следовательно, может привести к снижению уровня доступности ДОД. Рассматриваемый процесс совершенствования государственного финансового механизма развития системы дополнительного образования ресурсозатратен и неэффективен в условиях тенденции снижения доли государственных учреждений в системе ДОД.

Таким образом, в целях повышения уровня доступности учреждений ДОД, а также возрастания числа вовлеченных детей различных социальных групп, ограниченных как внешними барьерами доступности, так и их субъективными особенностями (мотивация и культурный капитал семьи, инвалидность ребенка и др.), государству совместно с субъектами сети организаций ДОД необходимо периодически проводить модернизацию системы ДОД с применением современных методов, инструментов и средств обеспечения доступности как на уровне регионов, так и на уровне отдельных учреждений.

Maтериаль и методы / Materials and methods. В процессе исследования использовались труды отечественных исследователей и практических деятелей в сфере ДОД, в частности таких авторов, как А. В. Золотарева, В. П. Мусина, О. И. Ануфриева, Л. Н. Буйлова, а также законодательные акты в части регулирования образовательной деятельности и статистическая сводная отчетность, предоставляемая Министерством просвещения РФ.

Исследование базируется на использовании системного подхода к изучаемому объекту. В процессе рассмотрения и исследования системы дополнительного образования детей в стране применялись общенаучные методы теоретического познания: методы статистического и логического анализа и синтеза, сравнения, дедукции и обобщения, технологии структурного и графического моделирования. Каждый из методов применялся адекватно его функциональным возможностям, что позволило обеспечить аргументированность и достоверность обобщений, выводов и положений, полученных в работе. 
Результаты и обсужсдение / Results and discussion. По результатам анализа ежегодно формируемой и публикуемой Министерством просвещения Российской Федерации статистической сводной отчетности выявлено, что количество учреждений ДОД с 2015 по 2018 гг. снизилось на $11,31 \%$, при этом численность занимающихся сократилась в среднем на 1031,77 тыс. человек. На рис. 1 проиллюстрирована динамика количества организаций ДОД в стране и динамика численности детей, занимающихся в этих учреждениях [на основе данных 4].
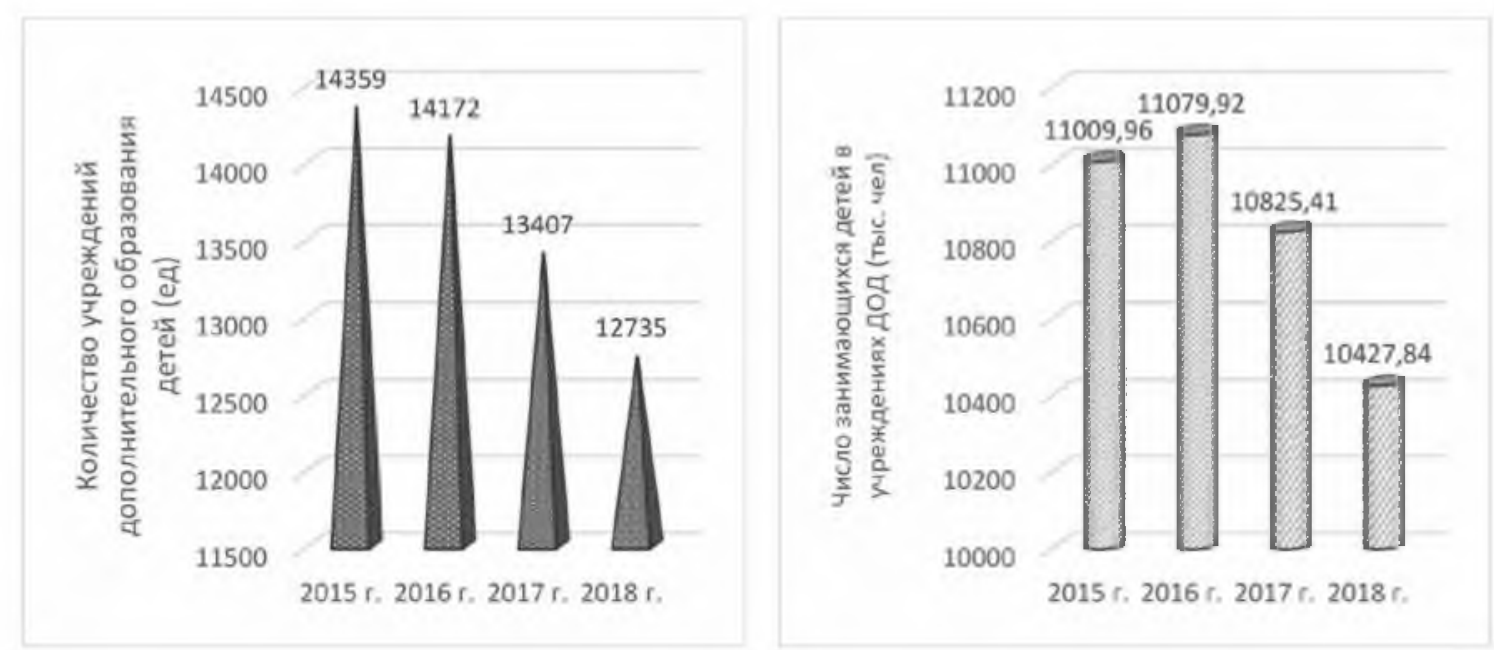

Рис. 1. Динамики количества организаций дополнительного образования детей и численности детей, занимающихся в них в 2015-2018 гг.

Наибольшая доля среди детей, занимающихся в рамках реализуемых программ дополнительного образования, приходится на детей в возрасте от 5 до 14 лет (более $75 \%$ мальчиков и 80 $\%$ девочек). Однако показатель охвата детей определенного возраста в целом не является единственным и всеобъемлющим критерием оценки доступности.

Исследования показывают, что спад числа субъектов, обеспечивающих ДОД, наблюдается в сфере государственных образовательных учреждений (ГОУ), тем временем негосударственный сектор оказания услуг дополнительного образования (НОУ), наоборот, отражает положительную тенденцию - численность учреждений за исследуемый период увеличилась почти в 2,5 раза. Таким образом, система ДОД претерпевает структурные трансформационные сдвиги, доля НОУ в сфере ДОД стабильно ежегодно возрастает, о чем свидетельствуют материалы таблицы.

Таблица

Динамика количества учреждений дополнительного образования детей в 2015-2018 гг.

\begin{tabular}{|c|c|c|c|c|c|c|c|c|c|c|}
\hline \multirow{3}{*}{$\begin{array}{c}\text { Учреждения ДОД } \\
\text { по направлениям } \\
\text { деятельности }\end{array}$} & \multicolumn{8}{|c|}{ Количество учреждений } & \multirow{2}{*}{\multicolumn{2}{|c|}{$\begin{array}{l}\text { TeмII pocta } 2018 \\
\text { к 2015, в \% }\end{array}$}} \\
\hline & \multicolumn{2}{|c|}{2015} & \multicolumn{2}{|c|}{2016} & \multicolumn{2}{|c|}{2017} & \multicolumn{2}{|c|}{2018} & & \\
\hline & $\begin{array}{l}\text { Всего, } \\
\text { ед. }\end{array}$ & $\begin{array}{l}\text { из них в } \\
\text { сельск. } \\
\text { местн. } \\
\end{array}$ & $\begin{array}{c}\text { Всего, } \\
\text { ед. }\end{array}$ & $\begin{array}{l}\text { из них в } \\
\text { сельск. } \\
\text { местн. } \\
\end{array}$ & $\begin{array}{l}\text { Всего, } \\
\text { ед. }\end{array}$ & \begin{tabular}{|l|} 
из них в \\
сельск. \\
местн. \\
\end{tabular} & $\begin{array}{c}\text { Всего, } \\
\text { ед. }\end{array}$ & $\begin{array}{l}\text { из них в } \\
\text { сельск. } \\
\text { местн. } \\
\end{array}$ & $\begin{array}{c}\text { Всего, } \\
\text { ед. }\end{array}$ & \begin{tabular}{|l} 
из них в \\
сельск. \\
местн. \\
\end{tabular} \\
\hline ВСЕГО (гр. $1+$ гр. 2) & 14359 & 3756 & 14172 & 3781 & 13407 & 3666 & 12735 & 3601 & 88,69 & 95,87 \\
\hline \multicolumn{11}{|c|}{ ГОСУДАРСТВЕННЫЕ ОБРАЗОВАТЕЛЬНЫЕ УЧРЕЖДЕНИЯ ДОД } \\
\hline $\begin{array}{l}\text { Работающих по всем } \\
\text { видам образовательной } \\
\text { деятельности }\end{array}$ & 3742 & 953 & 3549 & 941 & 3513 & 908 & 3410 & 905 & 91,13 & 94,96 \\
\hline Художественные & 4367 & 1442 & 4478 & 1528 & 4461 & 1479 & 4641 & 1461 & 106,27 & 101,32 \\
\hline
\end{tabular}




\begin{tabular}{|c|c|c|c|c|c|c|c|c|c|c|}
\hline \multirow{3}{*}{$\begin{array}{c}\text { Учреждения ДОД } \\
\text { по направ.лениям } \\
\text { деятельности }\end{array}$} & \multicolumn{8}{|c|}{ Количество учреждений } & \multirow{2}{*}{\multicolumn{2}{|c|}{$\begin{array}{c}\text { Темп роста } 2018 \\
\text { к 2015, в \% } \\
\end{array}$}} \\
\hline & \multicolumn{2}{|c|}{2015} & \multicolumn{2}{|c|}{2016} & \multicolumn{2}{|c|}{2017} & \multicolumn{2}{|c|}{2018} & & \\
\hline & $\begin{array}{l}\text { Всего, } \\
\text { ед. }\end{array}$ & \begin{tabular}{|l|} 
из них в \\
сельск. \\
местн. \\
\end{tabular} & $\begin{array}{l}\text { Всего, } \\
\text { ед. }\end{array}$ & $\begin{array}{l}\text { из них в } \\
\text { сельск. } \\
\text { местн. }\end{array}$ & $\begin{array}{l}\text { Всего, } \\
\text { ед. }\end{array}$ & $\begin{array}{l}\text { из них в } \\
\text { сельск. } \\
\text { месті. }\end{array}$ & $\begin{array}{l}\text { Всего, } \\
\text { ед. }\end{array}$ & $\begin{array}{c}\text { из них в } \\
\text { сельск. } \\
\text { местн. }\end{array}$ & $\begin{array}{l}\text { Всего, } \\
\text { ед. }\end{array}$ & \begin{tabular}{|l} 
из них в \\
сельск. \\
местн. \\
\end{tabular} \\
\hline Эколого-биологические & 219 & 26 & 204 & 29 & 196 & 30 & 174 & 25 & 79,45 & 96,15 \\
\hline Технические & 217 & 37 & 220 & 38 & 211 & 33 & 197 & 33 & 90,78 & 89,19 \\
\hline Туристско-краеведческие & 185 & 42 & 177 & 35 & 170 & 37 & 155 & 33 & 83,78 & 78,57 \\
\hline Спортивное & 4400 & 968 & 4183 & 971 & 3540 & 922 & 2859 & 885 & 64,98 & 91,43 \\
\hline Военно-патриотические & 26 & 3 & 17 & 1 & 17 & 1 & 18 & 0 & 69,23 & 0,00 \\
\hline Спортивно-технические & 41 & 4 & 34 & 3 & 47 & 9 & 27 & 4 & 65,85 & 100,00 \\
\hline Другие & 976 & 280 & 1015 & 227 & 889 & 233 & 804 & 239 & 82,38 & 85,36 \\
\hline ИТОГО (гр. 1) & 14173 & 3755 & 13877 & 3773 & 13044 & 3652 & 12285 & 3585 & 86,68 & 95,47 \\
\hline \multicolumn{11}{|c|}{ НЕГОСУДАРСТВЕННЫЕ ОБРАЗОВАТЕЛЬНЫЕ УЧРЕЖДЕНИЯ ДОД } \\
\hline $\begin{array}{l}\text { Работающих по всем } \\
\text { видам образовательной } \\
\text { деятельности }\end{array}$ & 40 & 1 & 63 & 2 & 90 & 5 & 105 & 5 & 262,50 & 500,00 \\
\hline Художественные & 8 & 0 & 11 & 0 & 11 & 0 & 11 & 0 & 137,50 & - \\
\hline Эколого-биологические & 0 & 0 & 0 & 0 & 0 & 0 & 0 & 0 & - & - \\
\hline Технические & 0 & 0 & 5 & 1 & 9 & 1 & 14 & 1 & - & - \\
\hline Туристско-краеведческие & 0 & 0 & 0 & 0 & 0 & 0 & 0 & 0 & - & - \\
\hline Спортивное & 45 & 0 & 32 & 1 & 37 & 3 & 42 & 4 & 93,33 & \\
\hline Военно-патриотические & 0 & 0 & 0 & 0 & 0 & 0 & 0 & 0 & - & - \\
\hline Спортивно-технические & 1 & 0 & 1 & 0 & 1 & 0 & 3 & 2 & 300,00 & - \\
\hline Другие & 92 & 0 & 183 & 4 & 215 & 5 & 275 & 4 & 298,91 & - \\
\hline ИТОГО (гр. 2) & 186 & 1 & 295 & 8 & 363 & 14 & 450 & 16 & 242,1 & 1600,0 \\
\hline
\end{tabular}

Происходящие изменения затрудняют процесс обеспечения возможности приобретения услуг ДОД для определенных групп обучающихся, т. к. доступность услуг учреждений ДОД в сельской местности не достигает уровня $20 \%$ из числа государственных учреждений и $5 \%$ - негосударственных учреждений.

В складывающейся ситуации для успешной реализации стратегических целей государства в сфере ДОД целесообразно определить основные направления деятельности субъектов системы ДОД, направленные на оказание содействия в обеспечении доступности образовательных услуг.

1. Государственная поддержка частных организаций ДОД посредством финансовых инструментов (льготы на налоги, субсидии и др.), а также социальной поддержки детей различных категорий, в том числе детей с ОВ3; детей, проживающих в сельской местности; детей из семей, находящихся в трудной жизненной ситуации; из малоимущих семей. Так, Министерство просвещения РФ (ранее Министерство образования и науки Российской Федерации) в конце 2017 года планировало ввести индивидуальные сертификаты на получение услуг по программам ДОД с адресной поддержкой доступности дополнительного образования для малообеспеченных и многодетных семей, семей, находящихся в трудной жизненной ситуации. Такой проект в пилотном режиме был запущен и активно реализовывался до разделения министерства на новые ведомства. Актуальная информация о процессе реализации данного проекта в информационных ресурсах отсутствует. 
2. Реализация мероприятий учреждениями ДОД по усовершенствованию условий предоставления дополнительных образовательных и развивающих услуг посредством модернизации организационно-управленческой среды, а также внедрения и развития системы вариативного обучения.

Процесс совершенствования системы субъекта ДОД на уровне отдельного учреждения, как правило, организовывается и реализуется руководителем учреждения и его управленческо-административным составом. При этом первостепенной задачей руководителя является проведение оценки доступности программ дополнительного образования и выделение основных условий, которые при их интеграционном взаимодействии позволят достичь максимально возможного уровня доступности услуг организации для каждой категории детей. К ним можно отнести такие, как:

- ценовая доступность, характеризующая возможность расходов потребителя, обладающего определенными доходами;

- территориальная (транспортная или пешеходная) доступность, определяющая условия физического доступа к объекту, где будет осуществляться потребление услуги;

- временная доступность, которая определяет время, когда потребителю возможно оказать услугу;

- организационная доступность, которая показывает, насколько просто / сложно получить доступ к услуге;

- информационная доступность, определяющая наличие и качество информации об услуге [3].

Следующий стадия процесса - формирование методики повышения степени доступности ДОД посредством построения алгоритма действий (рис. 2).

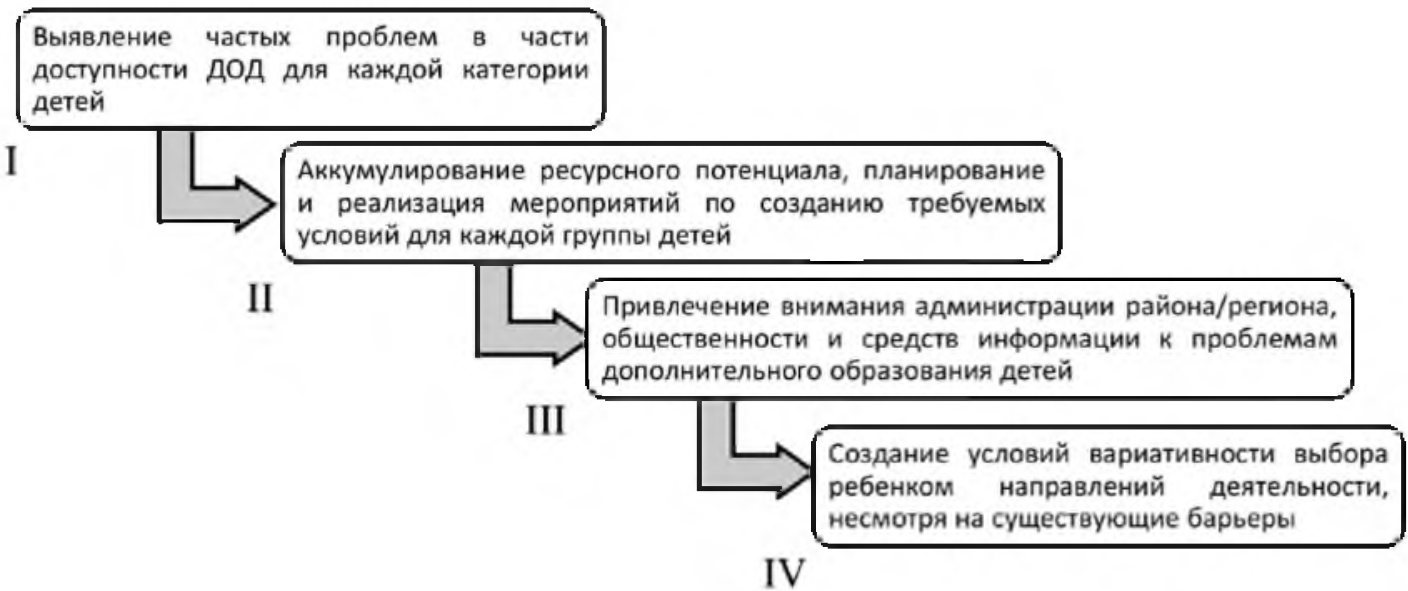

Рис. 2. Инструменты и средства повышения уровня доступности дополнительного образования (для руководителей образовательных организаций)

В процессе выявления наиболее весомых проблем в части доступности ДОД административно-управленческая команда одновременно оценивает потребности детей с ограниченными возможностями здоровья; детей, проживаюших в сельской местности; детей из семей, находящихся в трудной жизненной ситуации; детей из малоимуших семей, определяет особенности организации воспитательно-образовательного процесса и др.

Например, особенности организации образовательного (тренировочного) процесса в сельской местности является обеспеченность квалифицированным педагогическим персоналом. Насушной проблемой большинства сел страны является дефицит учреждений ДОД, в том числе 
культурно-образовательных и спортивных центров и соответственно специалистов дополнительного образования, что затрудняет удовлетворение образовательных потребностей детей, и по большей части дополнительное образование осуществляется на базе школ. Следовательно, проблема обеспечения доступности ДОД в сельской местности будет решена посредством создания требуемого уровня инфраструктуры и привлечения квалифицированного человеческого потенциала.

Методы, инструменты и средства создания руководителями образовательных организаций условий доступности ДОД, учитывающие потребности и особенности детей, проживающих в сельской местности, определяются на втором этапе алгоритма. Условно их можно классифицировать на средства внутриорганизационного воздействия и инструменты внешней поддержки. К первой группе можно отнести:

- создание условий для базовой профессиональной переподготовки педагогов сельской местности, а также специалистов других гуманитарных сфер для осуществления ими механизмов и инструментов качественного дополнительного образования

- создание программы привлечения молодых высококвалифицированных специалистов, готовых организовывать работу в сельских поселениях, включающей в себя компетентностную диагностику и элементы повышения квалификации;

- использование для учреждений ДОД тренинговых и модульных образовательных форм;

- механизм подготовки и внедрения индивидуальных проектных грантов для детей из сельской местности и др.

К примерам применения внешних инструментов обеспечения доступности можно отнести многосторонний договор о социальном партнёрстве, площадки для стажировки школьников на базе производственных предприятий.

Необходимость создания условия «ценовая доступность» обосновывается наличием большого количеством семей, имеющих низкий социально-экономический статус малоимущих семей и семей, находящихся в трудной жизненной ситуации.

Множество научных трудов, посвященных данной тематике, принадлежит российскому психологу-эксперту В. П. Мусиной. Она отмечает сложность решения проблемы доступности программ дополнительного образования для данной категория детей на микроуровне, т. к. учреждения ДОД часто предоставляют свои услуги на платной основе. Эффективность реализации проблемы доступности ДоД напрямую зависит от уровня оказываемой государством поддержки [5].

На практике выделяют следующие инструменты вовлечения в систему дОД детей из семей, имеющих низкий социально-экономический статус:

1) организация совместной деятельности по сопровождению детей из неблагополучных семей в процессе ДОД (органы социальной помощи, управление образования, служба занятости населения);

2) использование психологическо-консультативных видов работы с неблагополучными семьями, таких как убеждение, моральная поддержка, вовлечение в деятельность, сопереживание;

3) формирование системы профессиональной подготовки в части работы с детьми особой категории, позволяющей выполнять работу в выбранном направлении дополнительного образования;

4) организация диагностической, коррекционно-развивающей и просветительской работы, направленной на профессиональное самоопределение подростков и коррекцию возможных затруднений

5) организация внешнесетевого взаимодействия [5]. 
Наиболее сложной с позиции организации условий доступности ДОД рационально обозначить категорию детей с ОВ3 и инвалидностью. Для формирования данных условий необходимо создание и развитие инклюзивного обучения в системе учреждений, а следовательно:

- организация пространства самоопределения (самопознания, самоидентификации, саморазвития) обучающихся в эмоционально комфортных для них условиях;

- создание позитивно-конструктивного стиля отношения к детям, независимо от их способностей, физических, умственных, материальных и иных возможностей;

- поддержание непрерывной деятельности детей с учетом их индивидуальных особенностей и потребностей;

- обеспечение каждому ребенку открытой перспективы для добровольного выбора формы проведения своего свободного времени [2].

Методы и инструменты реализации данных условий определяются руководителем учреждения в соответствии с требованиями законодательства и принципами построения современной системы ДОД.

Реализация мероприятий по созданию справедливых условий доступности ДОД для последних двух категорий детей осуществляется в тесной взаимосвязи с внешней средой. С этой целью руководителю рекомендуется разработать личную модель взаимодействия субъектов внутренней и внешней среды системы ДОД (рис. 3).

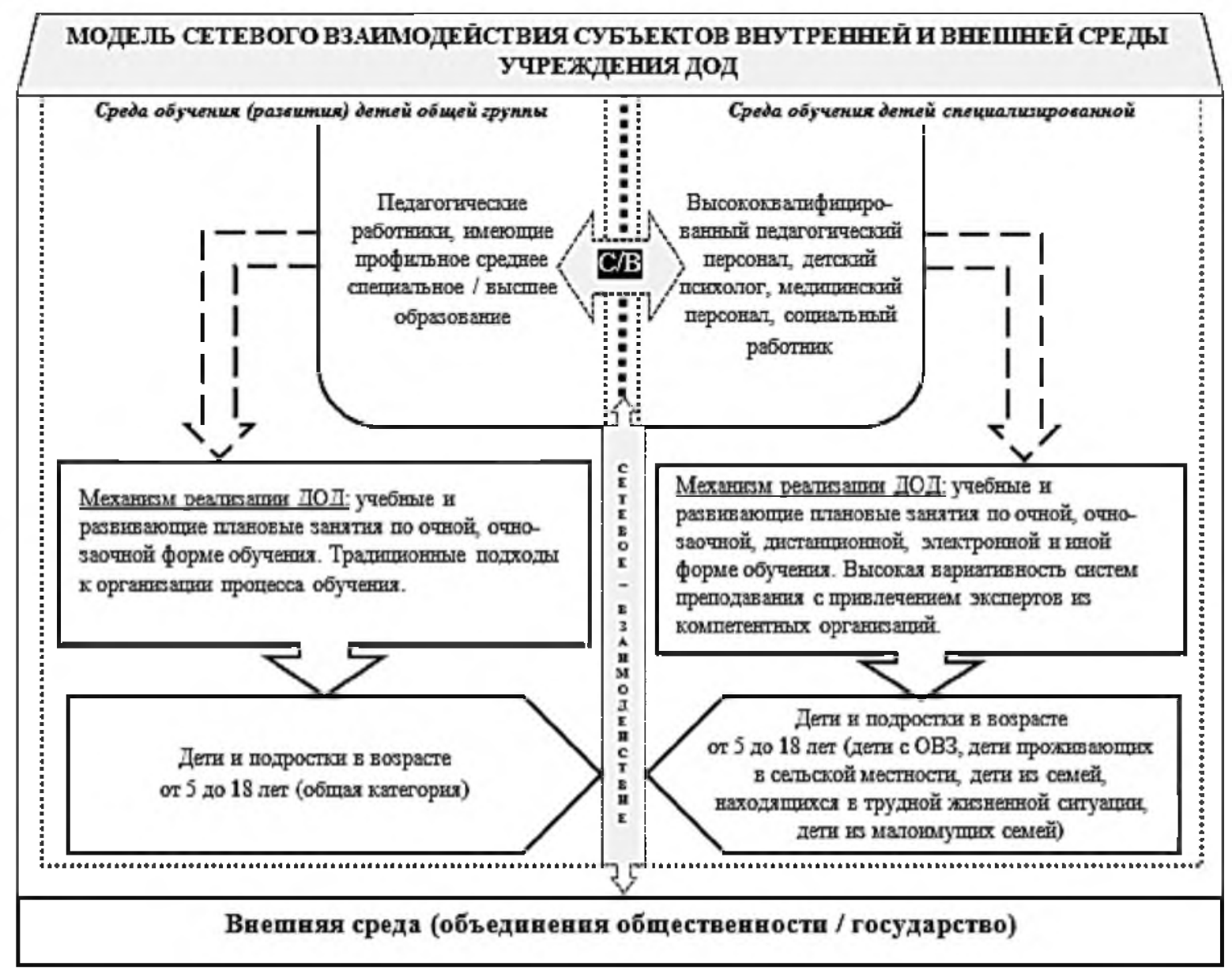

Рис. 3. Модель сетевого взаимодействия субъектов внутренней и внешней среды системы ДОД 
Таким образом качественный уровень воспитательно-образовательной деятельности учреждений ДОД важно обеспечивать с учетом социальных и физических потребностей каждой категории детей в отдельности, в таком случае результат деятельности учреждений позитивно скажется как на личностном росте индивида, так и на развитии общественного института в целом.

Заключение / Conclusion. Система дополнительного образования должна обеспечивать равенство получения образовательных услуг детьми всех социально-экономических категорий населения. Руководителям образовательных организаций важно использовать комплекс различных методов, инструментов и средств обеспечения доступности дополнительного образования детей различных категорий, в том числе детей с ограниченными возможностями здоровья; детей, проживающих в сельской местности; детей из семей, находящихся в трудной жизненной ситуации; из малоимущих семей.

\section{ЛИТЕРАТУРА И ИНТЕРНЕТ-РЕСУРСЫ}

1. Ануфриева О. И. Дополнительное образование детей и взрослых / О. И. Ануфриева // Среднее профессиональнос образование - 2018. - № 4. - С. 19-22.

2. Буйлова Л. Н. Технология разработки и оценки качества дополнительных общеобразовательных общеразвивающих программ: новое время - новые подходы : методическое пособие / Л. Н. Буйлова. Москва, 2015.

3. Золотарева А. В. Управление образовательной организацией. Развитие учреждения дополнительного образования детей: учебное пособие / А. В. Золотарева. - Москва, 2018.

4. Мусина В. П. Социальное сопровождение детей из неблагополучных семей на примере подросткового центра / В. П. Мусина // Psyjournal. - 2016. - № 2 (22). - С. 89-95.

5. https://edu.gov.ru/ - Министерство просвещения РФ.

\section{REFERENCES AND INTERNET RESOURCES}

1. Anufrieva O. I. Dopolnitel'noe obrazovanie detei i vzroslykh / O. I. Anufrieva // Srednee professional'noe obrazovanie. -2018 . - № 4. - S. 19-22.

2. Builova L. N. Tekhnologiya razrabotki i otsenki kachestva dopolnitel'nykh obshcheobrazovatel'nykh obshcherazvivayushchikh programm: novoe vremya - novye podkhody : metodicheskoe posobie / L. N. Builova. - Moskva, 2015

3. Zolotareva A. V. Upravlenie obrazovatel'noi organizatsiei. Razvitie uchrezhdeniya dopolnitel'nogo obrazovaniya detei: uchebnoe posobie / A. V. Zolotareva. - Moskva, 2018

4. Musina V. P. Sotsial'noe soprovozhdenie detei iz neblagopoluchnykh semei na primere podrostkovogo tsentra / V. P. Musina // Psyjournal. - SPb, 2016. - № 2 (22). - S. 89-95.

5. https://edu.gov.ru/ - Ministerstvo prosveshcheniya RF.

\section{СВЕДЕНИЯ ОБ АВТОРАХ}

Бабии Аниа Анатольевна, кандидат экономических наук, доцент кафедры экономической безопасности, учета и аудита ФГАОУ ВО «Северо-Кавказский федеральный университет». E-mail: delightful@bk.ru

Тер-Григорьянц Радмила Георгиевна, магистр экономики, директор Автономной некоммерческой организации «Научно-методический центр образования, воспитания и социальной защиты детей и молодежи "СУВӒГ"». E-mail: stag.fcpro@yandex.ru

Котова Галина Леонидовна, кандидат педагогических наук, руководитель отдела научных исследований и методических разработок Автономной некоммерческой организации «Научно-методический центр образования, воспитания и социальной защиты детей и молодежи “СУВАГ”». E-mail: stag.fcpro@yandex.ru

\section{INFORMATION ABOUT THE AUTHORS}

Anna Babich, $\mathrm{PhD}$ in Economics, Associate Professor Departments of Economic Security, Accounting and Auditing, North Caucasus FederalUniversity. E-mail: delightful $@$ bk.ru.

Radmila Ter-Grigoryantz, Master of Arts in Economics, Director of the Metodology Center for Education, Upbringing and Social Security of Children and Youth "SUVAG". E-mail: stag.fcpro $a$ yandex.ru

Galina Kotova, $\mathrm{PhD}$ (Pedagogy), head of the department of the Metodology Center for Education, Upbringing and Social Security of Children and Youth "SUVAG". E-mail: stag.fcpro@yandex.ru 